\title{
SDF-1/CXCR4 induces cell invasion through CD147 in squamous cell carcinoma of the hypopharynx
}

\author{
SATOSHI TOYOMA, SHINSUKE SUZUKI, YOHEI KAWASAKI and TAKECHIYO YAMADA
}

\begin{abstract}
Department of Otorhinolaryngology and Head and Neck Surgery, Akita University Graduate School of Medicine, Akita 010-8543, Japan
\end{abstract}

Received December 16, 2019; Accepted April 8, 2020

DOI: $10.3892 / \mathrm{ol} .2020 .11744$

\begin{abstract}
Hypopharyngeal squamous cell carcinoma (SCC) has a poor prognosis due to local invasion and metastasis. The chemokine receptor $\mathrm{CXC}$ chemokine receptor type 4 (CXCR4) and its ligand, stromal cell-derived factor 1 (SDF-1), play roles in tumor progression through unclear mechanisms. For the present study, we used a hypopharyngeal SCC cell line, FaDu, expressing CXCR4. We found that SDF-1 promotes migration and invasion of the FaDu cells. In addition, AMD3100, a specific antagonist of CXCR4, inhibited the binding of SDF-1 to CXCR4, resulting in a significant decrease in the FaDu cell migration induced by SDF-1. Stimulation of CXCR4 with SDF-1 induced an increase in the expression of CD147, a cell membrane protein; and this CD147 upregulation was abrogated by AMD3100. CD147 function-blocking antibodies also abolished the SDF-1-induced FaDu invasiveness. Our results suggested that SDF-1/CXCR4 mediate hypopharyngeal SCC cell migration and that CD147 is involved in the SDF-1/CXCR4-related tumor progression.
\end{abstract}

\section{Introduction}

Hypopharyngeal cancer (mostly squamous cell carcinoma (SCC)) is most common in the head and neck. Treating patients is difficult and they experience poor life quality due to problems eating, swallowing, vocalizing, and breathing; moreover, the prognosis remains particularly ominous, even

Correspondence to: $\mathrm{Dr}$ Shinsuke Suzuki, Department of Otorhinolaryngology and Head and Neck Surgery, Akita University Graduate School of Medicine, 1-1-1 Hondo, Akita, Akita 010-8543, Japan

E-mail:suzukis@med.akita-u.ac.jp

Abbreviations: CD147, cluster of differentiation-147; CXCR4, CXC chemokine receptor type 4; HNSCC, head and neck squamous cell carcinoma; SCC, squamous cell carcinoma; SDF-1, stromal cell-derived factor 1

Key words: CXCR4, SDF-1, CD147, HNSCC, hypopharynx, invasion among the head and neck cancers (1). These cancers also present high local invasiveness with neck lymph node and distant metastases (2), and approaches are needed to improve adjuvant therapy for hypopharyngeal cancer.

Chemokines are a superfamily of small cytokine-like proteins that can bind to the transmembrane domain and activate chemokine receptors, a family of seven transmembrane $G$ protein-coupled receptors (3). The chemokine family currently comprises over 40 members that are subdivided into groups based on their first two N-terminal cysteine residue motifs and binding to $\mathrm{G}$ protein-coupled receptors segmented based on chemokine subgroups (CXCR, CCR, CX3R1, XCR1) (4). Chemokines have various roles in vivo, including promoting mitosis and regulating apoptosis, survival, and angiogenesis $(5,6)$. These functions are beneficial for tumor progression, and chemokines are now recognized to be expressed in many tumor types (7).

In particular, the interaction between the CXC chemokine receptor type 4 (CXCR4) and its ligand stromal derived factor 1 (SDF-1), also known as CXCL12, has been shown to affect cell survival, proliferation, and migration in malignant tumors $(8,9)$. It was recently discovered that the expression of CXCR4 is involved in the metastasis of breast and prostate cancer cells cooperating with SDF-1 $(10,11)$. Thus, SDF-1/CXCR4 plays a role in the tumorigenesis of many cancers $(12,13)$.

Studies of SDF-1/CXCR4 have focused mainly on head and neck cancer. Research models conducted in head and neck SCC (HNSCC) cell lines or HNSCC nude mice have shown that the expression of SDF-1/CXCR4 promotes cell motility, proliferation, and metastasis via the upregulation of various pathways, such as ERK 1/2, NF-kB, and matrix metalloproteinase (MMP) (14-18). In addition, some clinical data have suggested that SDF-1/CXCR4-positive HNSCC tumors have high metastatic potential and poor outcomes (14,19-22). However, research on its correlation with other tumor-promoting factors is lacking.

CD147, also known as extracellular matrix metalloproteinase inducer (EMMPRIN), is a member of the immunoglobulin superfamily that is highly expressed in cancer cells. It causes a variety of malignant tumors, including $\operatorname{HNSCC}(23,24)$. Studies have attempted to elucidate the mechanisms underlying CD147-induced tumorigenesis in various types of cancer $(3,25)$, and the number of studies on the contribution of CD147 to the progression of HNSCC is increasing. We have previously reported that CD147 increases cell invasiveness, 
proliferation, and drug resistance via interaction with its ligand, cyclophilin A, in HNSCC cells [including in a hypopharyngeal cell line; (26)]. Moreover, CD147 expression is associated with cervical lymph node metastases in patients with tongue SCC (27). However, the role of CD147 in HNSCC tumorigenesis and its underlying mechanisms are not fully understood. In particular, although the relationship between CD147 and cytokines has been reported in various diseases $(28,29)$, many uncertainties remain in patients with cancer. The present study was aimed to investigate the mechanisms of tumor progression by SDF-1/CXCR4 in patients with hypopharyngeal cancer, thus assessing their association with CD147.

\section{Materials and methods}

Cell lines and cell culture. We purchased HSC-3, a human tongue SCC cell line, from the Japanese Collection of Research Bioresources Cell Bank (Osaka, Japan). FaDu, the cells from a human hypopharyngeal SCC cell line, were kindly gifted by the Department of Cell Biology and Morphology, Akita University Graduate School of Medicine (Akita, Japan); we used both cell lines for in vitro studies. All cells were maintained in the Dulbecco's modified Eagle's medium (DMEM; Merck KGaA) supplemented with $10 \%$ fetal bovine serum in a humidified atmosphere containing $5 \% \mathrm{CO}_{2}$ at $37^{\circ} \mathrm{C}$.

Western blotting. We detected protein expression using western blot analysis with actin as an internal control. We lysed cell lines in detergent containing $1 \% \mathrm{NP}-40,150 \mathrm{mmol} / \mathrm{l}$ $\mathrm{NaCl}, 1 \mathrm{mmol} / \mathrm{l}$ EDTA, $0.1 \mathrm{mmol} / 1$ phenylmethylsulfonyl fluoride, $1 \mu \mathrm{g} / \mathrm{ml}$ leupeptin, and $1 \mu \mathrm{g} / \mathrm{ml}$ aprotinin and determined the protein levels using the Bio-Rad Protein Assay method (Bio-Rad Laboratories). We separated $40 \mu \mathrm{g}$ of the total protein on $8 \%$ SDS-PAGE gels and transferred them to nitrocellulose membranes using a semidry transfer machine (Bio-Rad Laboratories). Next, we blocked membranes with $5 \%$ skimmed milk/TBS with Tween-20 solution for $1 \mathrm{~h}$ at room temperature, and incubated with primary antibodies in $5 \%$ skimmed milk in TBS-T overnight at $4^{\circ} \mathrm{C}$. After washing with TBS-T three times, we incubated the membranes for $1 \mathrm{~h}$ with horseradish-peroxidase-conjugated secondary antibody (Bio-Rad Laboratories) 1:3,000 diluted in 5\% skimmed milk in TBS-T. We rinsed the filters with TBS-T three times and developed the blot using Luminol Reagent (Santa Cruz Biotechnology, Santa Cruz, CA, USA) by autoradiography. The band intensities were analyzed using the ImageJ software (U. S. National Institutes of Health). We used the following primary antibodies: Rabbit anti-CXCR4 (1:1,000; Bioss), rabbit anti-CD147 (1:1,000; Santa Cruz Biotechnology), and mouse anti- $\beta$-actin (1:5,000; Merck Millipore).

Matrigel invasion and cell migration assays. We evaluated cell invasion and migration using in vitro using Matrigel-coated semipermeable modified Boyden inserts with a pore size of $8 \mu \mathrm{m}$ (BectonDickinson/Biocoat). We plated cells in duplicate at a density of $5 \times 10^{3}$ cells/well for the invasion assay or at $3 \times 10^{4}$ cells/well for the migration assay. Plating was carried out on serum-free DMEM with SDF-1 $(0.1 \mu \mathrm{g} / \mathrm{ml}$; Pepro Tech), AMD3100 (10 ng/ml; Abcam), anti-CD147 function-blocking antibody (10 $\mu \mathrm{g} / \mathrm{ml}$, UM-8D6, cat. no. 10R-CD147aHU;

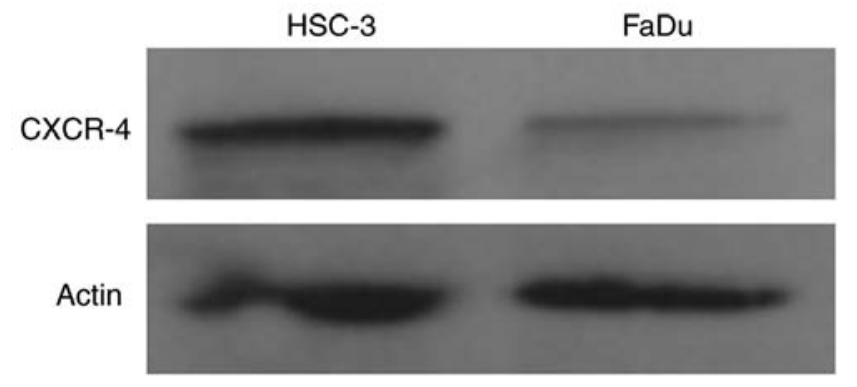

Figure 1. Hypopharyngeal squamous cell carcinoma cell line FaDu expresses CXCR4. CXCR4 protein expression detected by immunoblotting of the hypopharyngeal squamous cell carcinoma cell line FaDu. HSC-3 cells (a tongue squamous cell carcinoma cell line) were used as a positive control. The images show a representative immunoblot of CXCR4 levels in the cells. CXCR4, CXC chemokine receptor type 4.

Research Diagnostics), for which the blocking activity has been published $(30,31)$, or a combination of SDF-1 and AMD3100 for the migration assay or anti-CD147 function-blocking antibody for the invasion assay in the inserts. We plated the cells in 96-well plates to serve as loading controls. Both the insert and the holding well were filled with the same medium composition, but without serum. The insert contained no serum, whereas the lower well contained $10 \%$ FBS that served as a chemoattractant. After a $24-\mathrm{h}$ treatment at $37^{\circ} \mathrm{C}$ in a $5 \% \mathrm{CO}_{2}$ incubator, we gently wiped away the cells in the insert using a cotton swab. Cells on the reverse side of the insert were fixed and stained with Diff-Quik ${ }^{\circledR}$ (Sysmex) according to the manufacturer's instructions. Cells plated in 24-well plates were subjected to 3-(4,5-dimethylthiazol-2-yl)-2,5-diphenyltetrazolium bromide assays, and we normalized the cell numbers across the groups. We also adjusted the number of invading or migrating cells accordingly.

Proliferation assay. FaDu cells were plated in triplicate at a density of $3 \times 10^{4}$ cells/well and allowed to seed overnight in a 12 -well plate. Cells were then treated with SDF-1 $(0.1 \mu \mathrm{g} / \mathrm{ml})$, anti-CD147 function-blocking antibody $(10 \mu \mathrm{g} / \mathrm{ml})$, or a combination of SDF-1 and anti-CD147 function-blocking antibody in DMEM with $10 \%$ FBS. At selected time-points, we trypsinized the cells and stained them with trypan blue, and viable cells were counted using a hemocytometer.

Statistical analysis. Statistical analyses were performed using Statcel 3 (OMS Publishing). One-way ANOVA with post-hoc Tukey test was used to assess the statistically significant differences in proliferation, invasion, and migration studies. Data are presented as the mean \pm SD from experiments that were repeated at least three times. $\mathrm{P}<0.05$ was considered to indicate a statistically significant difference.

\section{Results}

Hypopharyngeal SCC cell expresses CXCR4. To investigate the function of CXCR4 in hypopharyngeal SCC, we measured the expression of CXCR4 in FaDu cells (established from hypopharyngeal SCC) by western blotting. At the same time, we also analyzed the expression of CXCR4 in HSC-3 (a cell line established from SCC of the tongue) as a control (32). 
A

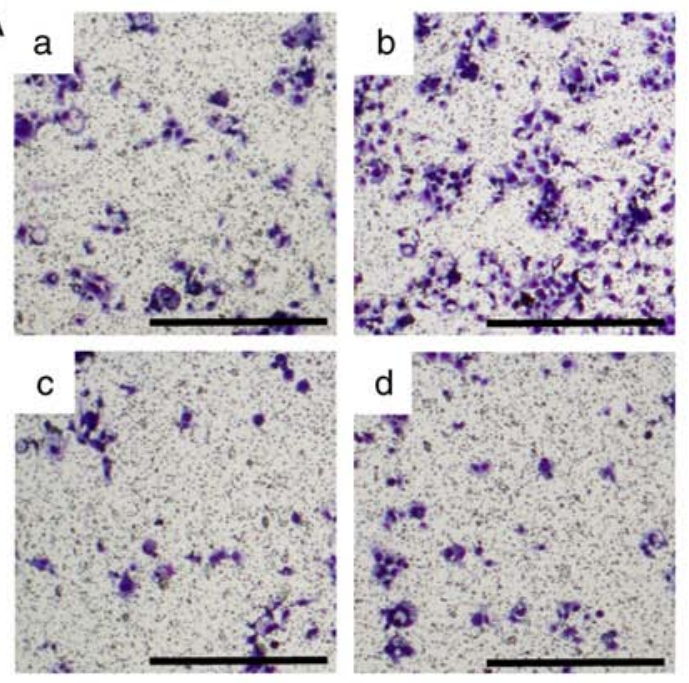

B

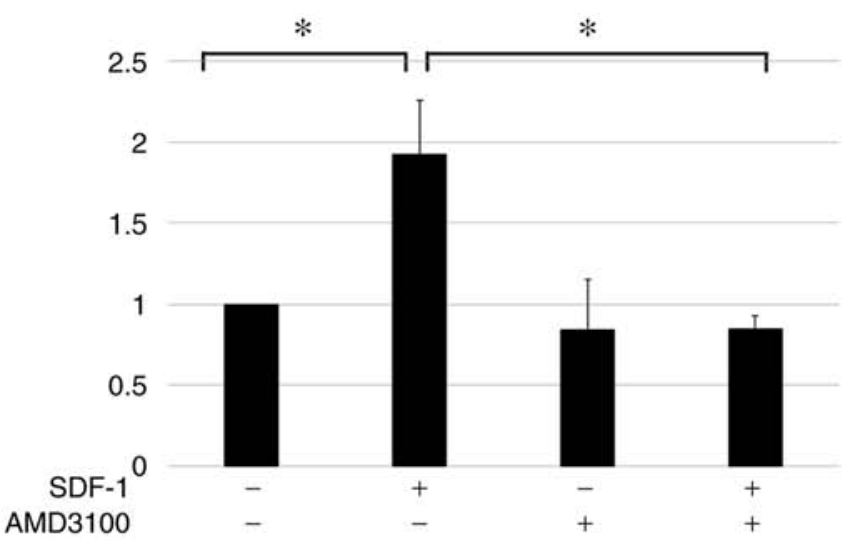

C $\quad 30$

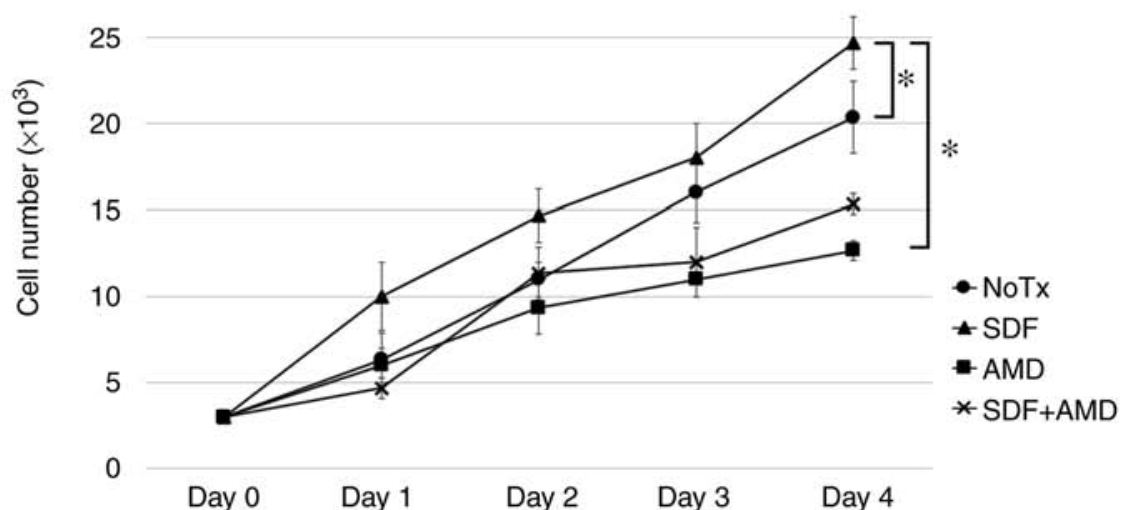

Figure 2. SDF-1 induces hypopharyngeal SCC cell migration via its interaction with CXCR4. Cell migration and proliferation ability of FaDu, a hypopharyngeal SCC cell, were evaluated after adding SDF-1 $(0.1 \mu \mathrm{g} / \mathrm{ml})$, AMD3100 $(10 \mathrm{ng} / \mathrm{ml})$, a combination of the agents or none. (A) Representative image of the migration assay results. FaDu cells were plated in the inserts in serum-free medium. Untreated cells were used as controls. (a) Control; (b) SDF-1; (c) AMD3100; and (d) combination of the agents. Scale bar, $100 \mu \mathrm{m}$. (B) Results are presented as fold-changes in migration relative to those in control cells FaDu cell migration increased in response to SDF-1 stimulation, whereas the addition of AMD3100 reversed this increase. Experiments were repeated three times, and fold migratory relative to control was expressed as the mean \pm standard deviation. ${ }^{*} \mathrm{P}<0.05$. (C) Proliferation assay of hypopharyngeal SCC cells treated with SDF-1 $(0.1 \mu \mathrm{g} / \mathrm{ml})$ and/or AMD3100 $(10 \mathrm{ng} / \mathrm{ml})$. Cells were plated in 12-well plates in DMEM with $10 \%$ FBS, and after $24 \mathrm{~h}$, the growth media was replaced with media containing each agent. Cells were harvested and counted by vital dye exclusion. Cell counts on days $1,2,3$ and 4 from three independent experiments are presented as the mean \pm standard deviation. ${ }^{*} \mathrm{P}<0.05$. SCC, squamous cell carcinoma; CXCR4, CXC chemokine receptor type 4; SCC, squamous cell carcinoma; SDF-1, stromal cell-derived factor 1.

Our results showed that FaDu cells express CXCR4 protein; however, the expression level was weak compared to that in the tongue SCC cell line HSC-3 (Fig. 1).

SDF-1/CXCR4 increases cell migration in hypopharyngeal $S C C$ cells. As tumor cell invasion and migration are important during the tumor progression cascade, controlling cell mobility is viewed as a target for clinical tumor suppression $(33,34)$. To understand the mechanisms underlying hypopharyngeal SCC cell invasion, we seeded FaDu cells into Boyden chambers and stimulated them with SDF-1.

The invasiveness of $\mathrm{FaDu}$ cells increased when the cells were co-cultured with SDF-1 $(\mathrm{P}<0.05)$ is shown in Fig. 2A and B. To determine whether this increased migration was mediated by an SDF-1-CXCR4 interaction, we added AMD3100, a CXCR4 antagonist (35). The AMD3100 treatment reversed the increased migration of $\mathrm{FaDu}$ cells $(\mathrm{P}<0.05)$, suggesting that SDF-1 induces hypopharyngeal SCC cell

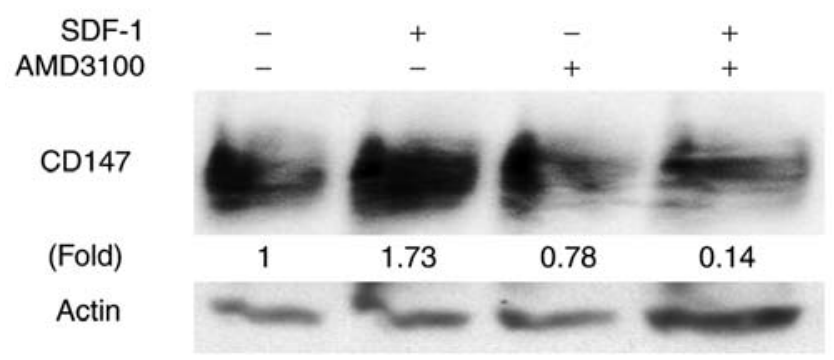

Figure 3. SDF-1/CXCR4 increases the expression of CD147 in hypopharyngeal squamous cell carcinoma cells. The expression of the epithelial protein $\mathrm{CD} 147$ was examined by western blot analysis. FaDu was treated with or without SDF-1 $(0.1 \mu \mathrm{g} / \mathrm{ml})$, AMD3100 $(10 \mathrm{ng} / \mathrm{ml})$, or with a combination of both agents for $48 \mathrm{~h}$. SDF-1 increased the expression of CD147 in FaDu cells, whereas the addition of AMD3100 reversed this increase. The experiment was repeated three times with similar results. Representative immunoblot of CD147 levels in the cells with quantitation of the relative expression of CD147 normalized to actin below the blot. CD147, cluster of differentiation-147; CXCR4, CXC chemokine receptor type 4; SDF-1, stromal cell-derived factor 1. 

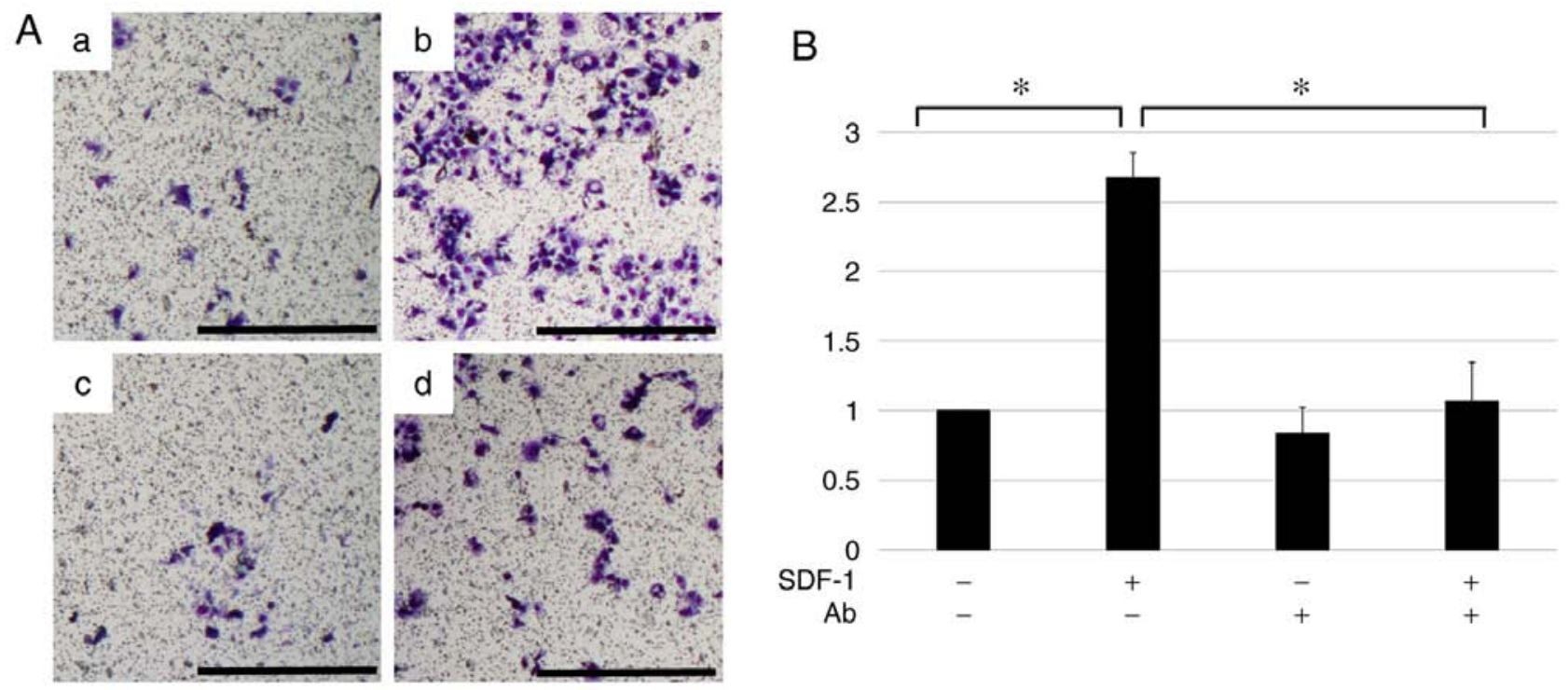

Figure 4. CD147 plays a critical role in SDF-1-induced hypopharyngeal SCC cell invasion. Cell invasiveness of FaDu, a hypopharyngeal SCC cell, was evaluated using an invasion assay. Cells were plated on inserts with or without SDF-1 $(0.1 \mu \mathrm{g} / \mathrm{ml})$, CD147 function-blocking antibody $(10 \mu \mathrm{g} / \mathrm{ml})$, or a combination of both agents in serum-free media with 10\% FBS, with the lower well serving as a chemoattractant; the CD147 function-blocking antibody decreased head and neck squamous cell carcinoma invasion during SDF-1 treatment. (A) Representative image of the invasion assay results. Untreated cells were used as controls (a) Control; (b) SDF-1; (c) CD147 function-blocking antibody; and (d) combination of the agents. Scale bar, $100 \mu \mathrm{m}$. (B) Results are presented as fold-changes in invasion relative to those in control cells. The experiment was repeated three times, and fold migratory relative to control was expressed as the mean \pm standard deviation. ${ }^{*} \mathrm{P}<0.05$. CD147, cluster of differentiation-147; SCC, squamous cell carcinoma; SDF-1, stromal cell-derived factor 1.

migration by stimulating CXCR4 (Fig. 2A and B). In addition, we evaluated the ability of SDF-1 to induce FaDu cell proliferation because during tumor progression, an increase in cell number is as important as cell mobility.

On day 4 the cells treated with SDF-1 increased significantly in number as compared to the untreated cells $(\mathrm{P}<0.05)$ (Fig. 2C). To determine whether this increase in proliferation ability was mediated by an SDF-1-CXCR4 interaction, we added AMD3100. AMD3100 treatment reversed the increase in proliferation of $\mathrm{FaDu}$ cells $(\mathrm{P}<0.05)$, suggesting that SDF-1 induces hypopharyngeal $\mathrm{SCC}$ cell proliferation by stimulating CXCR4 (Fig. 2C).

Our results suggest that the SDF-1/CXCR4 axis plays a key role in hypopharyngeal SCC cell mobility and proliferation, and may contribute to tumor progression.

SDF-1/CXCR4 induces expression of CD147 in hypopharyngeal SCC cell. CD147 expression is associated with tumor progression and poor prognosis in various types of solid tumors (including HNSCC). We previously found that CD147 mediates invasion, proliferation, and drug resistance in $\mathrm{FaDu}$ cells (26). Thus, for this study we hypothesized that CD147 is associated with CXCR4-induced tumorigenesis. We treated FaDu cells with SDF-1, and confirmed by western blotting that CD147 protein expression was up-regulated in these cells. In addition, AMD3100 suppressed the CD147 upregulation induced by SDF-1. Our results suggest that SDF-1/CXCR4 regulates CD147 expression in hypopharyngeal SCC (Fig. 3).

CD147mediates SDF-1/CXCR4-induced hypopharyngeal SCC cell invasion. The results shown in Figs. 2A-B and 3 indicate that SDF-1/CXCR4 induce cell mobility and CD147 expression in the hypopharyngeal SCC cell line FaDu. But, whether
CD147 was associated with the SDF-1/CXCR4-induced increment of mobility of the cells was unclear. Thus, we planned an invasion assay with $\mathrm{FaDu}$ cells using a function-blocking antibody of CD147 in the presence or absence of SDF-1. As shown in Fig. 4, SDF-1 induced invasiveness, and this effect was significantly diminished by addition of the CD147 function-blocking antibody. This suggests that SDF-1/CXCR4 induces invasion in hypopharyngeal SCC and that CD147 may play a role in SDF-1/CXCR4 induced tumorigenicity.

\section{Discussion}

The importance of SDF-1/CXCR4 in cancer progression has been reported, especially in the metastasis and proliferation of cancer cells. The association between solid cancers and SDF-1/CXCR4 interaction was first reported as a chemokine receptor that is highly expressed in primary and metastatic breast cancer lesions (10). In subsequent studies, signaling via SDF-1/CXCR4 in various solid tumors has been established as a chemokine receptor pathway that plays an important role in cancer progression and malignancy. SDF-1/CXCR4 has roles in oncogenesis, proliferation, metastasis, and angiogenesis in many cancers types, including lung cancer, melanoma, esophageal cancer, ovarian cancer, glioblastoma, and basal cell carcinoma cells $(8,9,12,13,36,37)$.

Analyses using molecular biology techniques have revealed that communication between CXCR4 and SDF-1 activates multiple signaling pathways to enhance tumor cell invasion and distant metastasis (38). In addition, CXCR4 cooperates with other transcription factors, such as NF- $\mathrm{KB}$ and Nanog, to help maintain the stemness of cancer stem cells as well as to induce metastatic behavior $(39,40)$. Therefore, SDF-1/CXCR4 is considered a new drug target for cancer treatment. 
Research on SSDF-1/CXCR4 molecules is also undergoing in patients with head and neck cancer. CXCR4 promotes migration and invasion of oral cancer cells (18) and SDF-1/CXCR4 is involved in the metastasis of laryngeal and hypopharyngeal cancers (14). For this process, MMP production via the ERK signaling pathway is essential, and this mechanism of SDF-1/CXCR4 molecules in patients with head and neck cancer has been elucidated (14). Studies have reported that CXCR4 expression in primary tumors is involved not only in the local recurrence of head and neck cancer (22) but also in cervical lymph node metastasis and distant metastasis of hypopharyngeal cancer (14). Moreover, SDF-1/CXCR4 expression has been shown to be a negative prognostic factor after postoperative radiotherapy for head and neck cancer $(21,41)$.

Therefore, clarifying the mechanisms of SDF-1/CXCR4 is important to overcome the therapeutic resistance of HNSCC.

Through our experiments, we confirmed CXCR4 expression in FaDu cells. A study has confirmed that FaDu cells express CXCR4 but not its ligand SDF-1 (42). Thus, we used exogenous SDF-1 for experiments on the interaction between SDF-1 and CXCR4.

In this study, we found that CXCR4 was involved in FaDu cell invasion and proliferation.

This was similar to the result of a study that used oral cancer cells (16). On the other hand, it was reported that CXCR4 was not involved in cell proliferation in HEp-2, an SCC of the larynx cell line (43). Therefore, these reports indicate that CXCR4 has different effects depending on the sub-location even within the same type of head and neck cancer and that detailed examination is necessary depending on the tumor site.

CD147 is associated with various physiological actions in cells, mainly via the production and activation of MMP (44). These are also beneficial for tumor progression. The correlation between the expression of CD147 in tumors and poor prognosis has been widely observed in individuals with solid tumors including HNSCC (45). It has been reported that CD147 is involved in MMP production, cell invasion, cell proliferation, and EMT in head and neck cancer cells $(26,46)$. Moreover, we have reported that CD147 expression in tongue cancer patients is positively correlated with lymph node metastasis (23). Thus, the involvement of CD147 in cancer progression has been gradually established. Furthermore, the role of CD147 as a therapeutic target for cancer has been studied, and its antitumor effects are expected for head and neck cancer $(47,48)$.

It is known that a targeting strategy is very important and epidermal growth factor receptor (EGFR) antibody is already in clinical use for head and neck cancer (49). In addition, recent studies have reported that the antitumor effect is further enhanced by simultaneously targeting multiple tumorigenic factors $(34,50)$. We also have reported that head and neck cancer progression can be suppressed synergistically by combining the inhibition of EGFR and CD147 (51).

These results suggest that because of the complex pathways of cancer progression, inhibition of a single tumor-related factor is not sufficient for tumor control. For a more effective antitumor effect, it is necessary to simultaneously inhibit a plurality of factors related to the factor of interest.

In this study, we showed that CD147 expression was enhanced after the stimulation of CXCR4 by SDF-1. This enhanced expression of CD147 was abrogated by AMD3100, an inhibitor of CXCR4. In addition, the enhancement of cell infiltration induced by SDF-1/CXCR4 was suppressed by inhibiting CD147. These results indicate that CD147 acts as a mediator of the SDF-1/CXCR4 pathway and that it is involved in the invasion induced by SDF-1/CXCR4 in hypopharyngeal cancer cells.

These results suggest a possibility that not only would SDF-1/CXCR4 be a therapeutic target, but also that targeting CD147 simultaneously with SDF-1/CXCR4 may be a new and effective strategy for treating hypopharyngeal cancer.

On the other hand, the inhibition of infiltration induced by the SDF-1/CXCR4 was only partial after CD147 inhibition. This suggests that one of the SDF-1/CXCR4-induced tumor progression pathways is via CD147. Elucidation of these pathways is required for more powerful control of head and neck cancer progression.

\section{Acknowledgements}

Not applicable.

\section{Funding}

The present study was supported by Grant-in-Aid for Scientific Research (C) (grant no. 18K09337) from The Ministry of Education, Culture, Sports, Science and Technology, Japan.

\section{Availability of data and materials}

The datasets used and analyzed during the present study are available from the corresponding author on reasonable request.

\section{Authors' contributions}

SS conceived and designed the experiments. SS, ST and YK performed the experiments. SS analyzed data and contributed to writing of the manuscript. TY performed data analysis and interpretation. All authors read and approved the final manuscript.

\section{Ethics approval and consent to publication}

Not applicable.

\section{Patient consent for publication}

Not applicable.

\section{Competing interests}

The authors declare that they have no competing interests.

\section{References}

1. Carvalho AL, Pintos J, Schlecht NF, Oliveira BV, Fava AS, Curado MP, Kowalski LP and Franco EL: Predictive factors for diagnosis of advanced-stage squamous cell carcinoma of the head and neck. Arch Otolaryngol Head Neck Surg 128: 313-318, 2002.

2. Ho AS, Kim S, Tighiouart M, Gudino C, Mita A, Scher KS, Laury A, Prasad R, Shiao SL, Ali N, et al: Association of quantitativemetastatic lymph node burden with survival in hypopharyngeal and laryngeal cancer. JAMA Oncol 4: 985-989, 2018. 
3. Zlotnik A and Yoshie O: Chemokines: A new classification system and their role in immunity. Immunity 12: 121-127, 2000.

4. Proudfoot AEI: Chemokine receptors: Multifaceted therapeutic targets. Nat Rev Immunol 2: 106-115, 2002.

5. Zhou Y, Larsen PH, Hao C and Yong VW: CXCR4 is a major chemokine receptor on glioma cells and mediates their survival. J Biol Chem 277: 49481-49487, 2002.

6. Burger JA and Kipps TJ: CXCR4: A key receptor in the crosstalk between tumor cells and their microenvironment. Blood 107: 1761-1767, 2006

7. Balkwill F: Cancer and the chemokine network. Nat Rev Cancer 4: 540-550, 2004.

8. Scala S, Ottaiano A, Ascierto PA, Cavalli M, Simeone E, Giuliano P, Napolitano M, Franco R, Botti G and Castello G: Expression of CXCR4 predicts poor prognosis in patients with malignant melanoma. Clin Cancer Res 11: 1835-1841, 2005.

9. Barbero S, Bonavia R, Bajetto A, Porcile C, Pirani P, Ravetti JL, Zona GL, Spaziante R, Florio T and Schettini G: Stromal cell-derived factor 1alpha stimulates human glioblastoma cell growth through the activation of both extracellular signal-regulated kinases 1/2 and Akt. Cancer Res 63: 1969-1974, 2003.

10. Müller A, Homey B, Soto H, Ge N, Catron D, Buchanan ME, McClanahan T, Murphy E, Yuan W, Wagner SN, et al: Involvement of chemokine receptors in breast cancer metastasis. Nature 410: 50-56, 2001.

11. Taichman RS, Cooper C, Keller ET, Pienta KJ, Taichman NS and McCauley LK: Use of the stromal cell-derived factor-1/CXCR4 pathway in prostate cancer metastasis to bone. Cancer Res 62 : $1832-1837,2002$

12. Jiang YP, Wu XH, Shi B, Wu WX and Yin GR: Expression of chemokine CXCL12 and its receptor CXCR4 in human epithelial ovarian cancer: An independent prognostic factor for tumor progression. Gynecol Oncol 103: 226-233, 2006.

13. Chen GS, Yu HS, Lan CC, Chow KC, Lin TY, Kok LF, Lu MP, Liu $\mathrm{CH}$ and Wu MT: CXC chemokine receptor CXCR4 expression enhances tumorigenesis and angiogenesis of basal cell carcinoma. Br J Dermatol 154: 910-918, 2006.

14. Tan CT, Chu CY, Lu YC, Chang CC, Lin BR, Wu HH, Liu HL, Cha ST, Prakash E, Ko JY and Kuo ML: CXCL12/CXCR4 promotes laryngeal and hypopharyngeal squamous cell carcinoma metastasis through MMP-13-dependent invasion via the ERK1/2/AP-1 pathway. Carcinogenesis 29: 1519-1527, 2008.

15. Samara GJ, Lawrence DM, Chiarelli CJ, Valentino MD, Lyubsky S, Zucker S and Vaday GG: CXCR4-mediated adhesion and MMP-9 secretion in head and neck squamous cell carcinoma. Cancer Lett 214: 231-241, 2004.

16. Hong JS, Pai HK, Hong KO, Kim MA, Kim JH, Lee JI, Hong SP and Hong SD: CXCR-4 knockdown by small interfering RNA inhibits cell proliferation and invasion of oral squamous cell carcinoma cells. J Oral Pathol Med 38: 214-219, 2009.

17. Rehman AO and Wang CY: CXCL12/SDF-1 alpha activates NF-kappaB and promotes oral cancer invasion through the Carma3/Bcl10/Malt1 complex. Int J Oral Sci 1: 105-118, 2009.

18. Yu T, Wu Y, Helman JI, Wen Y, Wang C and Li L: CXCR4 Promotes oral squamous cell carcinoma migration and invasion through inducing expression of MMP-9 and MMP-13 via the ERK signaling pathway. Mol Cancer Res 9: 161-172, 2011.

19. Ishikawa T, Nakashiro KI, Hara S, Klosek SK, Li C, Shintani S and Hamakawa H: CXCR4 expression is associated with lymph-node metastasis of oral squamous cell carcinoma. Int J Oncol 28: 61-66, 2006.

20. Katayama A, Ogino T, Bandoh N, Nonaka S and Harabuchi Y: Expression of CXCR4 and its down-regulation by IFN-gamma in head and neck squamous cell carcinoma. Clin Cancer Res 11: 2937-2946, 2005.

21. De-Colle C, Mönnich D, Welz S, Boeke S, Sipos B, Fend F, Mauz PS, Tinhofer I, Budach V, Jawad JA, et al: SDF-1/CXCR4 expression in head and neck cancer and outcome after postoperative radiochemotherapy. Clin Transl Radiat Oncol 5: 28-36, 2017.

22. Knopf A, Bahadori L, Fritsche K, Piontek G, Becker CC, Knolle P Krüger A, Bier H and Li Y: Primary tumor-associated expression of CXCR4 predicts formation of local and systemic recurrency in head and neck squamous cell carcinoma. Oncotarget 8: 112739-112747, 2017.

23. Caudroy S, Polette M, Tournier JM, Burlet H, Toole B, Zucker $S$ and Birembaut P: Expression of the extracellular matrix metalloproteinase inducer (EMMPRIN) and the matrix metalloproteinase-2 in bronchopulmonary and breast lesions. J Histochem Cytochem 47: 1575-1580, 1999.
24. Suzuki S, Sato M, Senoo H and Ishikawa K: Direct cell-cell interaction enhances pro-MMP-2 production and activation in co-culture of laryngeal cancer cells and fibroblasts: Involvement of EMMPRIN and MT1-MMP. Exp Cell Res 293: 259-266, 2004.

25. Hibino T, Sakaguchi M, Miyamoto S, Yamamoto M, Motoyama A, Hosoi J, Shimokata T, Ito T, Tsuboi R and Huh NH: S100A9 is a novel ligand of EMMPRIN that promotes melanoma metastasis. Cancer Res 73: 172-183, 2013.

26. Takahashi M, Suzuki S and Ishikawa K: Cyclophilin A-EMMPRIN interaction induces invasion of head and neck squamous cell carcinoma. Oncol Rep 27: 198-203, 2012.

27. Suzuki S, Honda K, Nanjo H, Iikawa N, Tsuji T, Kawasaki Y, Yamazaki K, Sato T, Saito H, Shiina K and Ishikawa K: CD147 expression correlates with lymph node metastasis inT1-T2 squamous cell carcinoma of the tongue. Oncol Lett 14: 4670-4676, 2017.

28. Shi WP, Ju D, Li H, Yuan L, Cui J, Luo D, Chen ZN and Bian H: CD147 promotes CXCL1 expression and modulates liver fibrogenesis. Int J Mol Sci 19: 1145, 2018.

29. Peng C, Zhang S, Lei L, Zhang X, Jia X, Luo Z, Huang X, Kuang Y, Zeng W, Su J and Chen X: Epidermal CD147 expression plays a key role in IL-22-induced psoriatic dermatitis. Sci Rep 7: 44172, 2017.

30. Bordador LC, Li X, Toole B, Chen B, Regezi J, Zardi L, Hu Y and Ramos DM: Expression of emmprin by oral squamous cell carcinoma. Int J Cancer 85: 347-352, 2000.

31. Koga K, Nabeshima K, Aoki M, Kawakami T, Hamasaki M, Toole BP, Nakayama J and Iwasaki H: Emmprin in epithelioid sarcoma: Expression in tumor cell membrane and stimulation of MMP-2 production in tumor-associated fibroblasts. Int J Cancer 120: 761-768, 2007.

32. Ishikawa T, Nakashiro KI, Klosek SK, Goda H, Hara S, Uchida D and Hamakawa H: Hypoxia enhances CXCR4 expression by activating HIF-1 in oral squamous cell carcinoma. Oncol Rep 21: 707-712, 2009.

33. Asakage T, Yokose T, Mukai K, Tsugane S, Tsubono Y, Asai M and Ebihara S: Tumor thickness predicts cervical metastasis in patients with stage I/II carcinoma of the tongue. Cancer 82: 1443-1448, 1998

34. Koppikar P, Choi SH, Egloff AM, Cai Q, Suzuki S, Freilino M, Nozawa H, Thomas SM, Gooding WE, Siegfried JM and Grandis JR: Combined inhibition of c-Src and epidermal growth factor receptor abrogates growth and invasion of head and neck squamous cell carcinoma. Clin Cancer Res 14: 4284-4291, 2008.

35. Jung YH, Lee DY, Cha W, Kim BH, Sung MW, Kim KH and Ahn SH: Antitumor effect of CXCR4 antagonist AMD3100 on the tumorigenic cell line of BHP10-3 papillary thyroid cancer cells. Head Neck 38: 1479-1486, 2016.

36. Spano JP, Andre F, Morat L, Sabatier L, Besse B, Combadiere C, Deterre P, Martin A, Azorin J, Valeyre D, et al: Chemokine receptor CXCR4 and early-stage non-small cell lung cancer: Pattern of expression and correlation with outcome. Ann Oncol 15: 613-617, 2004.

37. Koishi K, Yoshikawa R, Tsujimura T, Hashimoto-Tamaoki T, Kojima S, Yanagi H, Yamamura T and Fujiwara Y: Persistent CXCR4 expression after preoperative chemoradiotherapy predicts early recurrence and poor prognosis in esophageal cancer. World J Gastroenterol 12: 7585-7590, 2006.

38. Zhou W, Guo S, Liu M, Burow ME and Wang G: Targeting CXCL12/CXCR4 axis in tumor immunotherapy. Curr Med Chem 26: 3026-3041, 2017.

39. Jung MJ, Rho JK, Kim YM, Jung JE, Jin YB, Ko YG, Lee JS, Lee SJ, Lee JC and Park MJ: Upregulation of CXCR4 is functionally crucial for maintenance of stemness in drug-resistant non-small cell lung cancer cells. Oncogene 32: 209-221, 2013.

40. Es-Haghi M, Soltanian S and Dehghani H: Perspective: Cooperation of Nanog, NF- $\kappa \mathrm{B}$, and CXCR4 in a regulatory network for directed migration of cancer stem cells. Tumour Biol 37: 1559-1565, 2016

41. De-Colle C, Menegakis A, Mönnich D, Welz S, Boeke S, Sipos B, Fend F, Mauz PS, Tinhofer I, Budach V, et al: SDF-1/CXCR4 expression is an independent negative prognostic biomarker in patients with head and neck cancer after primary radiochemotherapy. Radiother Oncol 126: 125-131, 2018.

42. Wolff HA, Rolke D, Rave-Fränk M, Schirmer M, Eicheler W, Doerfler A, Hille A, Hess CF, Matthias C, Rödel RM and Christiansen H: Analysis of chemokine and chemokine receptor expression in squamous cell carcinoma of the head and neck (SCCHN) cell lines. Radiat Environ Biophys 50: 145-154, 2011. 
43. Zhu C, Pan Y, He B, Wang B, Xu Y, Qu L, Bao Q, Tian F and Wang S: Inhibition of CD147 gene expression via RNA interference reduces tumor cell invasion, tumorigenicity and increases chemosensitivity to cisplatin in laryngeal carcinoma Hep2 cells. Oncol Rep 25: 425-432, 2011.

44. Vu TH and Werb Z: Matrix metalloproteinases: Effectors of development and normal physiology. Genes Dev 14: 2123-2133, 2000.

45. Rosenthal EL, Shreenivas S, Peters GE, Grizzle WE, Desmond R and Gladson CL: Expression of extracellular matrix metalloprotease inducer in laryngeal squamous cell carcinoma. Laryngoscope 113: 1406-1410, 2003.

46. Suzuki S, Toyoma S, Tsuji T, Kawasaki Y and Yamada T: CD147 mediates transforming growth factor- $\beta 1$-induced epithelial-mesenchymal transition and cell invasion in squamous cell carcinoma of the tongue. Exp Ther Med 17: 2855-2860, 2019.

47. Landras A, de Moura CR, Jouenne F, Lebbe C, Menashi S and Mourah S: CD147 is a promising target of tumor progression and a prognostic biomarker. Cancers (Basel) 11, 2019.

48. Dean NR, Newman JR, Helman EE, Zhang W, Safavy S, Weeks DM, Cunningham M, Snyder LA, Tang Y, Yan L, et al: Anti-EMMPRIN monoclonal antibody as a novel agent for therapy of head and neck cancer. Clin Cancer Res 15: 4058-4065, 2009.
49. Vermorken JB, Herbst RS, Leon X, Amellal N and Baselga J: Overview of the efficacy of cetuximab in recurrent and/or metastatic squamous cell carcinoma of the head and neck in patients who previously failed platinum-based therapies. Cancer 112: 2710-2719, 2008

50. NozawaH,HowellG,SuzukiS,ZhangQ,Qi Y,Klein-Seetharaman J, Wells A, Grandis JR and Thomas SM: Combined inhibition of PLC $\{$ gamma $\}-1$ and c-Src abrogates epidermal growth factor receptor-mediated head and neck squamous cell carcinoma invasion. Clin Cancer Res 14: 4336-4344, 2008.

51. Suzuki S and Ishikawa K: Combined inhibition of EMMPRIN and epidermal growth factor receptor prevents the growth and migration of head and neck squamous cell carcinoma cells. Int J Oncol 44: 912-917, 2014.

This work is licensed under a Creative Commons Attribution-NonCommercial-NoDerivatives 4.0 International (CC BY-NC-ND 4.0) License. 